Revista de Derecho

\title{
La tragicomedia de la administración municipal en La Ley de Herodes
}

Tragicomedy of the municipal administration on La Ley de Herodes

\section{Eddy Chávez Huanca}

Universidad Continental, Huancayo, Perú

echavez_77@hotmail.com

DOI: https://doi.org/10.32719/26312484.2019.31.6

Fecha de recepción: 15 de marzo de 2018

Fecha de aprobación: 26 de febrero de 2019

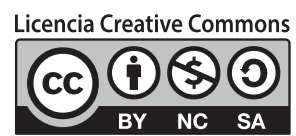




\section{RESUMEN}

El presente artículo relata, a través de un análisis de la película La Ley de Herodes, el ejercicio del poder local, la precariedad municipal y corrupción en la que no pocas veces están involucradas las autoridades municipales. Vemos la degradación de Juan Vargas, el alcalde del pueblo, como se sirve de la ley para darle una aparente legalidad a sus actos ilícitos para sostenerse en el poder y someter a la población. El cine resulta un instrumento idóneo para la discusión de temas difíciles como el de la corrupción y sus connotaciones, que terminan estableciendo una cultura de la ilegalidad que pone en entredicho la ética y la eficacia del derecho.

PalABRAS Clave: derecho, cine, municipio, alcalde.

\section{ABSTRACT}

This article relates through an analysis of the movie The Law of Herod, the exercise of local power, municipal precariousness and corruption in which the municipal authorities are not infrequently involved. We see the degradation of Juan Vargas, the Mayor of the town, as he uses the law to give an apparent legality to his illicit acts in order to sustain himself in power and subdue the population. Thus, cinema is an ideal instrument for discussing difficult issues such as corruption and its connotations that end up establishing a culture of illegality that challenges the ethics and effectiveness of law.

KeYwords: Law, Cinema, Municipality, Mayor.

\section{EL DRAMA DE LA VERDAD: EN EL DOLOR AJENO ESTÁ LA DIVERSIÓN}

"Todo se lo debemos a nuestro partido". Gobernador Fidel López

"A veces uno tiene que hacer cosas que a uno no le gusta, esa es la canija Ley de Herodes". Alcalde Juan Vargas

$\mathrm{R}$ especto a la elección ${ }^{1}$ vía sufragio de nuestras autoridades políticas, a todo nivel (nacional, regional o local), cabe resaltar la figura del ballotage la cual obliga

1. Perú, Constitución Política del Perú, 29 de diciembre de 1993. Art. 2, inc. 17: A participar, en forma individual o asociada, en la vida política, económica, social y cultural de la nación. Los ciudadanos tienen, 
a decidir sin mayor información, y en una suerte de escenario de albur. En Perú, mayoritariamente, elegimos sin tener mayor responsabilidad, guiándonos por la idea de lo que socialmente ha mostrado el candidato. En los hechos, la forma de elegir tiene un carácter personalista fruto de la ausencia de organizaciones políticas que muestren una historia, ideario y objetivos políticos, sumado a una marcada tendencia a una vida caudillista, elementos que aún no terminamos de comprender y que son ajenos a las teorías clásicas o modernas de la ciencia política occidental.

En lo concerniente al poder local, la precariedad del sistema ya es un tema vencido históricamente, como una suerte de evasión resultante de una mala elección. Las frases populares que retratan a las flamantes autoridades que llegaron por azar son una suerte de consuelo de incautos, de decir no que nos merecemos a los gobernantes que tenemos, sino qué tarde nos damos cuenta de a quién hemos elegido, lo que resulta en buena cuenta el reflejo de lo que somos: un mar de improvisaciones, dándole una cabida desmedida al orden espontáneo de nuestra organización social; ese es el punto.

Para atender esa complejidad de la realidad de los gobiernos locales, hemos de dar cuenta de la ficción fílmica, aquella que retrata, no pocas veces con humor negro, los devaneos de la corrupción, incompetencia y crisis permanente en la que terminan sumidos los pueblos que caen en manos de burgomaestres maliciosos. Una de las películas que retrata al típico alcalde de una comuna olvidada en las entrañas de la tierra es La Ley de Herodes de Luis Estrada (México, 1999).

Siempre hemos destacado la manera amistosa -por su factible acceso- en que el cine puede proponer reflexión o discusión sobre temas vitales. Esta no es la excepción. Dicha sencillez para comunicar -sin perder el rigor- también debe ser manifestada de manera permanente en el ámbito jurídico. Cuando se exponen con mejor detalle los dilemas, menos palabras; entre más ordenado, solo lo preciso. Abundar en argumentos y propuestas trasciende e importa más cuando la complejidad de lo que se discuta haga necesaria dicha reflexión que abunde en palabras.

Ejemplo de lo sencillo es la labor que Francesco Carnelutti relata en una serie de escritos ${ }^{2}$ reunidos para "el gran público no especialista", respecto del drama que resulta estar involucrado en un proceso judicial. Carnelutti nos dice que una manera de vivir la vida de los demás es a través de la fantasía; uno se imagina cómo podría ser su vida, cómo alcanzar los sueños, que al menos mentalmente el hombre lleve su libertad a fronteras insospechadas y derroche su imaginación por senderos sorprendentes, hasta llegar incluso a tener como ciertas esas fantasías; ¿acaso entonces el hombre tiene necesidad de divertirse a costa de otro? El bufón de hoy en día nos podría decir

conforme a ley, los derechos de elección, de remoción o revocación de autoridades, de iniciativa legislativa y de referéndum.

2. Francesco Carnelutti, Cómo nace un proceso (Bogotá: Temis, 2012). 
las verdades sin herir, hasta ocasionaría risas en los perjudicados, con la facilidad que tiene su humor incluso para relatarnos las noticias trágicas que nos comunicase.

Dónde nos queda ir o qué hacer para poder reír: ¿cine, teatro, televisión, comedias al aire libre? La vivencia lúdica es una necesidad connatural al ser humano, algunas veces llevada al paroxismo de ver sangre, el boxeo, la tauromaquia, las fiestas populares llenas de misticismo y religiosidad, quién dice hasta fanatismo que pone al límite la vida misma y la ajena. Queda ¿tolerar? que esto causa placer o genera rentas, es decir, asumir el clásico límite de la libertad de que no lo involucren a uno si es que no queremos.

La tragicomedia del municipio representada en el cine llega a todos, a todos aquellos que, además de entretener, se quieran enterar de lo que está pasando con las autoridades locales. Si bien sirve además de divertimento, uno se pregunta, ¿y mi alcalde? Tan embustero, tan cual cosa, tan esto, que mucho le falta de correcto y competente y mucho le sobra de Juan Vargas, el alcalde de San Pedro de los Saguaros, personaje central de la película que sirve de engranaje para retratar el ejercicio del poder local, la precariedad municipal y la corrupción.

Esta película es una manifestación del cine con el perfil icónico de una autoridad local de un país (México), pero resulta el reflejo de una circunstancia de un continente. De este tipo de autoridades está plagada América hispana, donde este alcalde puede ser de cualquier lado. Una característica hispana es la falta de compromiso para elegir como nuestras autoridades a los más idóneos. ${ }^{3}$

La troupé de Luis Estrada manifiesta ese tipo de personajes en su trilogía La Ley de Herodes (1999), Un mundo maravilloso (2006), El infierno (2010), donde, disparatadamente, se muestran los delirios de una sociedad que ha aprendido a vivir en un mar de contradicciones comunes exaltadas en tono de ironía, donde cada personaje representa la vida común del hispano, ya sea el que se fue de ilegal y volvió peor que antes, o aquel que no le quedó más que volverse parte del crimen; los niños que siguen la ruta del crimen de sus padres y, sobre todo, esa cultura popular criminal que cobra arraigo e influye en el día a día de todos quienes viven en dicho escenario.

\section{LO CÓMICO DE LA REALIDAD}

El poder local en el Perú está manifestado, al día de hoy, con autonomía del Ejecutivo, ya sea teniendo encima la descentralización del poder a través de los gobiernos regionales o el acceso a los gobiernos locales mediante listas de candidatos casi siem-

3. Plinio Apuleyo Mendoza, Carlos Alberto Montaner y Álvaro Vargas Llosa, Manual del perfecto idiota latinoamericano (Barcelona: Plaza \& Janés, 1996). 
pre nuevos que solo se presentan para un proceso en particular, todas ellas conformadas a iniciativa de los ciudadanos que deseen participar para poder representar y tener al mismo tiempo una cuota de poder.

En esta aún joven etapa donde se promueve la descentralización, y que ya vivimos con ejercicio de los gobiernos regionales, ha imperado el caudillismo como una suerte de remedo de lo que es el poder central. En estos tiempos se le reclama a las autoridades locales que tienen poca capacidad de gestión y falta de operatividad para el gasto público, lo cual es paradójico. Antes se reclamaba la falta de atención del gobierno central a toda la población en su conjunto, en base a la crisis económica y política, se argumentaba que no se podía atender a plenitud todas las necesidades de la población, ahora el reclamo es otro. Debido a que existe capacidad económica, sigue faltando capacidad de gestión.

Por otro lado, se pide no pocas veces que se evite por todos los medios posibles la aparición de los denominados "caudillos", lo que incluso tiene posibilidades en una base jurídica que promueve los personalismos (por ejemplo, el derecho electoral peruano promueve el voto preferencial para la elección de congresistas), ello no permite dar paso a propuestas políticas institucionales a largo plazo y mucho menos que estas sean continuas para ser mejoradas, revisadas permanentemente, facilitando así la proliferación de organizaciones políticas aparentes y que solo fomentan la promoción de una sola persona hacia la detentación del poder, el caudillismo perfecto avalado por los mecanismos democráticos. Sin embargo, no hay que ser trágicos, un cambio legislativo debe fomentar el surgimiento de nuevas organizaciones políticas, por etapas. Si bien es teatral la precariedad de cómo se organizan estas nuevas opciones políticas, hay que advertir que otro tanto ocurrió en otras latitudes, respecto de cómo se conformaron, en sus orígenes, los actuales partidos fuertes y tradicionales de las democracias occidentales avanzadas.

Otra faceta es ver cómo se les entrega las riendas a ciudadanos que forman parte de minorías o han sido desplazados históricamente en relación a las cuotas de poder de participación política. Una suerte de "a ver qué hace" y "dejemos que estropee las cosas". Así, se dice, se quedarán tranquilos los votantes, y "los de siempre" habrán de volver al poder, es decir, se establece una delegación de oportunidad de poder donde se espera que la administración de gobierno sea fallida, y si va siendo exitosa, se les desestabiliza. Para el caso peruano "los de siempre" es la oligarquía, que, sea virreinato o república, han detentado el poder y ha tenido las habilidades para preservarlo. Al respecto, Bourricaud señala lo siguiente:

Este grupo (el oligárquico) había aprendido a preservar -o, al menos, así parecía- su posición dominante en un mundo y en una región en los que sus homólogos extranjeros ya habían perdido mucho de su poder anterior. Es evidente, por ejemplo, que la recuperación limitada, parcial, violenta, agresiva y abusiva realizada en la década de 1930 en el caso peruano, en vez del surgimiento de una política de tipo populista como se dio en el caso de 


\section{Fotograma 1. Juan Vargas, el pervertido alcalde de San Pedro de los Saguaros}

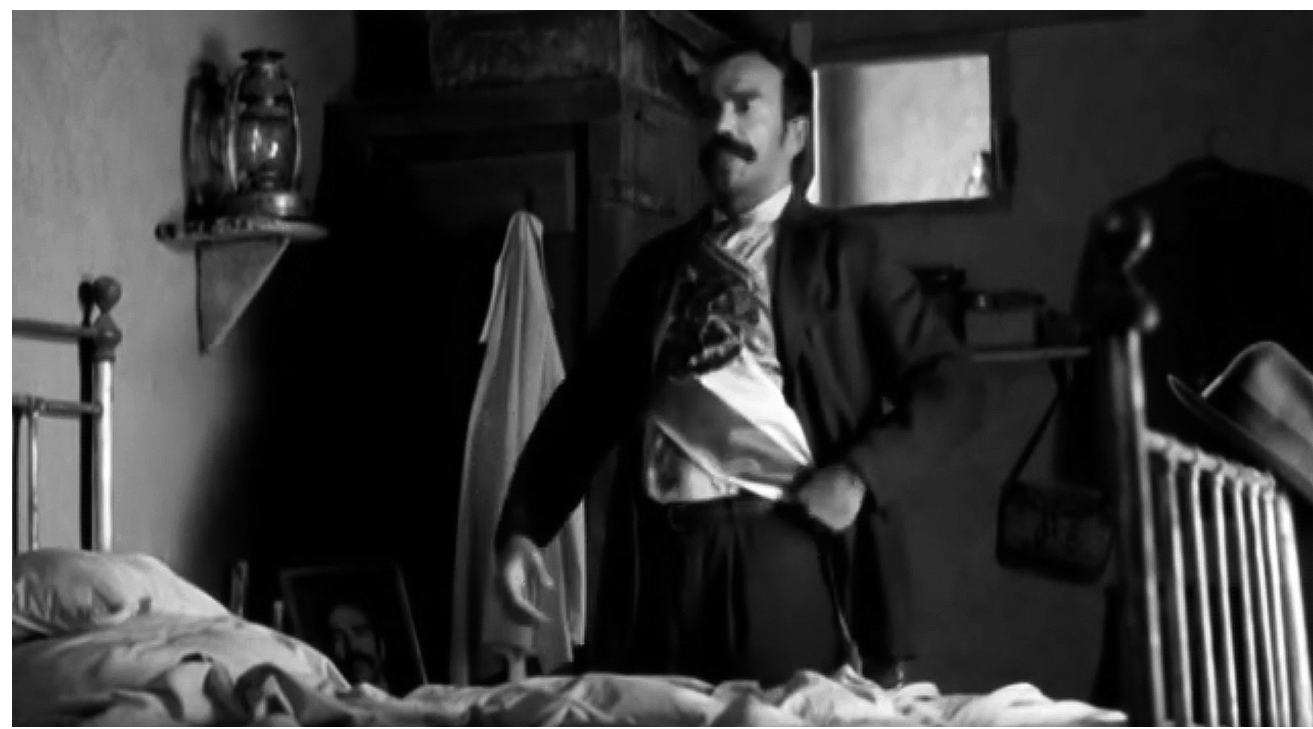

Fuente: Luis Estrada, La Ley de Herodes, DVD (México: Bandidos Films, 1999).

Argentina o en otros países de más peso, fue la última oportunidad, o el último chance que tuvo este grupo [...] para prolongar el sostenerse en la cúspide del control del país. ${ }^{4}$

Lo que esperamos de quienes nos representan es todo aquello que aspiramos, hasta todo aquello que no somos pero idealizamos. Finalmente, recibimos solamente lo que como sociedad hemos desarrollado, y si hay outsiders sentados en los estamentos de representación política es porque no hemos consolidado las instituciones de participación y se ha preferido la decisión espontánea -en su peor versión- y no razonada que nos lleva a escoger, a última hora, una autoridad elegida al azar y esperamos que sean mejores que nosotros, Savater señala lo siguiente respecto de cómo es que queremos a nuestras autoridades:

Los "padres" de la colectividad también tienen que ofrecer fuerza y conocimientos para hacerse obedecer. Deben ser hábiles cazadores, feroces guerreros, brujos poderosos, grandes constructores de edificios y obras públicas, capaces de derrotar a los enemigos, prevenir las inundaciones y las sequías, zanjar las disensiones entre facciones opuestas o entre intereses individuales,

4. François Bourricaud, Poder y sociedad en el Perú contemporáneo (Lima: Instituto de Estudios Peruanos, 2017), 28. 
y además tienen que inventar y organizar buenas fiestas en la que los miembros del grupo se sientan ligeros, libres de rutinas y de trabajos, fundidos con los demás en juergas sublimes... ¡Uf, no les falta trabajo, no, a los Padres de la Patria! Pero en fin, para eso les pagamos. ${ }^{5}$

\section{SOBRE EL MUNICIPIO}

El municipio como unidad política administrativa nace luego de la conquista del mundo antiguo por el Imperio romano. Los romanos permitían a algunas de las ciudades que dominaban, como una gracia especial, elegir a sus gobernantes y dirigir su propia política:

Tales ciudades eran llamadas Municipium, sus ciudadanos electores se convirtieron en cives municipies y los demás fueron llamados incolae, que eran los peregrinos sin derecho a voto. Con el tiempo, Roma extiende el régimen municipal a todos los pueblos que conquistó gracias a la Ley Julia Municipalis y, de ese modo, llegó esta institución a la península ibérica. A la caída del Imperio romano, el municipio conservó en España la organización y la autonomía antiguas. En la época de los visigodos cada ciudad tenía una institución denominada Conventus Publicus Vecinorum, o Asambleas de los hombres libres, que realizaba diversas funciones administrativas y judiciales. ${ }^{6}$

Sobre el municipio como institución política, Martins señala lo siguiente:

[E]jerce poder público, de carácter estatal, dentro de su competencia. Sus autoridades desempeñan cargos gubernativos, de carácter político, y los problemas que debe resolver son -al decir de Adolfo Posada-inevitablemente políticos. Su función no es meramente administrativa, de ejecución, sino gubernativa; organizando los servicios públicos municipales; planificando la realización de las obras públicas; dictando normas generales, de carácter legislativo, que se imponen obligatoriamente a todos los habitantes de su territorio; ejerciendo la policía municipal y decidiendo problemas políticos de orden social y económicofinancieros. ${ }^{7}$

Martins le añade a ello las características administrativas y territoriales, en razón de que se debe procurar por el bienestar de la población dándole mantenimiento a los bienes y preservando los espacios públicos, así como promover la convivencia basada en factores de buena vecindad.

5. Fernando Savater, Política para Amador (Barcelona: Ariel, 1993), 21.

6. Daniel Hugo Martins, "Regímenes municipales contemporáneos", en El Municipio, ed. por Jorge R. Vanossi (Buenos Aires: Ediciones Ciudad Argentina, 1984), 28.

7. Ibíd., 29. 
Ya en la época de la reconquista, los monarcas de los ibéricos, en la lucha contra los árabes, con sentido de defensa, estimulaban el nacimiento de poblaciones de fronteras a los que dotaban de "fueros", ${ }^{8}$ que después se extendieron a otros pueblos. Los municipios españoles eran auténticamente democráticos. Se respetaba y se hacía efectivo el principio de igualdad ante la ley. Todos tenían el derecho de participar en las elecciones municipales y ni aun el rey podía intervenir en ellas; la violación de domicilio se castigaba, y se castigaba con pena doble a los funcionarios porque se entendía como afrenta a la fe pública y el título más alto que podía exhibir un hombre era el de "vecino". ${ }^{9}$ Lo narrado abunda en fuentes, en un especial que preparó la Revista del Foro sobre el municipio, además de relatar su historia y problemas de gobernanza, dan cuenta de cómo es que arribó la institución del municipio castellano al Nuevo Mundo:

Pero el florecimiento de los municipios españoles terminó con el absolutismo de los reyes. Fue fecha nefasta para ellos el 23 de abril de 1521, cuando las tropas de Carlos V derrotaron a los comuneros de Castilla en la batalla de Villalar, y el poder central fue recortando la autonomía de las ciudades con el nombramiento de los gobernadores, corregidores y alcaldes mayores, que se ceñía a las cédulas, cartas e instrucciones que emanaban de la Corona. Es, en este período, es decir, en su plena decadencia, que el municipio español llega a América. ${ }^{10}$

\section{LOS ALCALDES EN EL CINE}

En la propuesta de Hollywood han sido retratados, sobre todo de manera accidental. Está, por ejemplo, Perdidos en Nueva York de Sam Weisman (USA, 1999), donde uno encuentra al alcalde en un cóctel, en cenas benéficas o rodeado de hombres

8. Fuero municipal: Así se llamaba en España el cuerpo de leyes concedido a alguna ciudad o villa para su gobierno y la administración de justicia. Los fueros municipales han sido muchos: se dieron cuando se empezó a expulsar a los moros y hacer la reconquista. Estos fueros quedaron derogados con la publicación del Fuero real y de las Partidas; pero fue preciso restablecerlos por las muchas reclamaciones a que dio lugar su abolición. Este es uno de los males de la legislación; pues para el bienestar y la tranquilidad de los pueblos se debe procurar en cuanto sea posible que las leyes sean generales. En Francisco García Calderón, Diccionario de la legislación peruana, 2. ${ }^{a}$ ed. (Lima: Imprenta del Estado, por E. Aranda, 1977), 1003.

9. Ibíd., 1826. Vecino. Vecindad: Se llama vecino el que habita con otros en un mismo pueblo, barrio o casa, en habitación independiente. Vecindad es la razón o calidad de vecino que uno tiene en un pueblo, por la habitación o domicilio durante el tiempo señalado por la ley. V. Domicilio y Ausente. En todas las declaraciones que se tomen en causas criminales, se debe preguntar a los reos su vecindad; omitiéndose esta pregunta cuando ya conste del proceso (31. E. Pen.)

10. Colegio de Abogados de Lima, Revista del Foro, año LIII, n. ${ }^{\circ} 2$ (mayo-agosto 1966): 11. 
influyentes, manifestando su poder y su influencia social en la comunidad. La serie de televisión The Boss, da vida a un alcalde sin escrúpulos, enfermo, lleno de intrigas en medio del poder. En la serie se representa también el decurso de las ciudades, su margen evolutivo tanto en infraestructura como en el desarrollo de sus vecinos, tanto si tiende a liberal o a conservador. Están aquellos alcaldes de las grandes urbes, como Rudolph Giuliani por ejemplo, quien ha sido referido en constantes oportunidades, desde una ciudad de Nueva York recuperada bajo su autoridad, hasta los eventos que la asolaron por el ataque terrorista $(9 / 11)$.

Los alcaldes en Perú, aquellos de las ciudades urbanas, no han sido de interés para el cine peruano. En sí, ningún tipo de autoridad local lo ha sido de manera principal, resultando su presencia solo un elemento decorativo o exótico. Si la problemática, por así decirlo, de aquello que ofrece el cinematógrafo se ha circunscrito a la fórmula del argumento estereotipado de aquel cine latinoamericano donde el argumento de violencia y un aderezo de fantasía con happy end, imita torpemente las recetas del mainstream norteamericano.

La autoridad local del medio rural está retratada sobre todo en películas de violencia política: el alcalde en los hechos es uno más entre sus iguales -su liderazgo es de apariencias-, con los mismos miedos, sin el aparato coercitivo, acompañado de paisajes de pueblos olvidados, donde solo tiene a su cargo una oficina desvencijada, un escudo y una bandera del Perú. Por ejemplo, en el caso de la película La vida es una sola de Marianne Eyde (Perú, 1992), un municipio vive en la encrucijada sobre a quién acudir, si ante los militares, para que apoyen la defensa de su pueblo, que no cuenta siquiera con un puesto de policía, aunque sabe que se van a ir, estarán un rato, rastrillarán, gritarán algo, arengarán que los apoyan, pero finalmente se van a ir. Luego, llegarán los terroristas. La autoridad política se encuentra entre dos fuegos, considera que mejor es callar, no decir nada, salvar la vida, hablar implica ir a la guerra o terminar muerto al ser señalado como soplón.

El alcalde se convierte entonces en un elemento figurativo, que manifestaba el abandono del Estado de las poblaciones que se encuentran en el Ande peruano. Librado a su suerte, no hay mayor distinción entre quién es autoridad y un poblador común, no se distingue la investidura, salvo porque este te diga "soy el alcalde". La ficción relata entonces una visión en este caso cercana a la verdad; no tiene el prejuicio centralista de cómo ven a "los otros" con o sin razón. Los alcaldes del Perú rural, de fines del siglo XX se acercan mucho a cómo el cine de humor negro los retrata, sin poder, sin distinción, sin presupuesto, simplemente como una autoridad figurativa, como telón de fondo (irónico) de una comedia o aquel que representa al poder político debilitado quizá por un agente externo.

El cine de Hollywood se ha concentrado sobre todo en las autoridades políticas del Ejecutivo. Sobre el tema de sus presidentes, hay para escribir y describir páginas 
e imágenes en buena cantidad. Como habíamos anotado, en Perú la puesta en escena de alcaldes resulta secundaria; tal como sucede con el alcalde Paiva de Pantaleón y las visitadoras de Francisco Lombardi (Perú, 1999), el alcalde de la película Bajo la piel de Francisco Lombardi (Perú, 1996) y con El alcalde y la política de Luis María Delgado (España, 1980), esta última película cómica sobre el tema de las elecciones. Así, el repertorio fílmico alcanza un sinnúmero de puestas en escena sobre este tipo de autoridades.

El poder local ha sido puesto de manifiesto en la narrativa indigenista Lituma en los Andes, de Mario Vargas Llosa, Los perros hambrientos, de Ciro Alegría, Todas las sangres, de José María Arguedas son novelas que buscan el entendimiento del poder local en el Perú, donde, en ejemplos marcados por la complejidad de la otredad, se advierte que la pugna y disfrute del poder tiene comportamientos endogámicos, se da una suerte de rechazo a cuadros ajenos al entorno familiar; todo se abastece por confianza o compadrazgo, detalle importante para entender la distribución del poder al día de hoy, en donde el nepotismo o las alianzas interfamiliares marcan el paso del control del poder en Perú.

Ante lo expuesto, quien tenga interés por merodear o cortejar el poder (en la presentación que fuera) tiene una manera de acercarse democráticamente a tales actividades, en donde todos interactúan como iguales; reflejo popular de ello es la canción Fiesta, de Joan Manuel Serrat, al menos por un momento, donde todos, ya sean patrones u obreros, ya sea en el deporte o en el baile, al menos mientras dure la actividad, equilibran sus intereses, mirarse para conocerse mejor respecto de estas actividades y cómo se dan en el Ande peruano. Sobre ello, el antropólogo Juan Ansión señala: “Asimismo, aparece la relación con los encuentros deportivos. Es posible que el fútbol siga cumpliendo en la actualidad una función similar, pues es notorio el entusiasmo por ese deporte, siendo el campo de fútbol el único terreno plano (o casi plano) en todos los pueblos y comunidades de la sierra". ${ }^{11}$

Las competencias donde se manifiestan el poder de unos o la habilidad de otros es parte común en todas las culturas; no hay privilegios ante ello, y si un grupo de gente es más guerrero que otro, por ejemplo, en justas deportivas o en lo que se asemeje, se configura un medir de fuerzas con posibles competidores, rivales de turno o simplemente una exhibición sobre cómo es que deben hacerse las cosas:

De modo general, la cultura andina parece haber enfatizado ese aspecto de competencia en muchos niveles, como forma de construir y reproducir lo social. Recordemos también,

11. Juan Ansión, “Autoridad y democracia en la cultura popular: una aproximación desde la cultura andina", Allpanchis Phuturinga, n. ${ }^{\circ} 33$ (1989): 66. 
en ese sentido, las justas verbales llenas de humor, el contrapunteo en las canciones, las competencias en el baile y en especial las de los danzantes de tijeras. Todas estas formas tienden, a través de un ambiente festivo, a reducir el conflicto y tratarlo en una suerte de microcosmos de acuerdo a normas conocidas y respetadas. ${ }^{12}$

\section{DAR, DAR, RECIBIR, RECIBIR}

Si se advierte en La Ley de Herodes, el flamante alcalde llega con su auto y su mujer al miserable pueblo. No trae nada, solo el lema del gobierno de turno, "Modernidad, paz, progreso y justicia social", y cubre así una plaza no apetecida por nadie. El partido político en el poder desea tener presencia en dicha localidad, y para ello envían a un anónimo y prescindible correligionario. Nadie en el partido de gobierno desea que, por un incidente menor, se vea afectada la continuidad en el poder.

De acuerdo a lo que el poblador andino entiende por autoridad, esta no necesita solamente el reconocimiento jurídico, sino también debe existir un reconocimiento social, en el caso peruano. El mundo andino, para ser precisos, está vinculado a una suerte de rituales y compromisos de quién manda para con el pueblo, desde el pago a la tierra (Pachamama), que el día de hoy también se manifiesta con una suerte de monumentalidad hacia la divinidad, siempre con fuerza hacia la madre naturaleza. No por poco hay monumentos dedicados a los frutos comestibles de provecho como la maca o el maíz, a los recursos naturales que identifican bienestar para el poblador del Ande. El que manda debe ser generoso, mostrarse dadivoso, debe llegar siempre con algo, no solo con el documento oficial que lo reconoce como autoridad; la población espera recibir no solo dones, sino además parabienes, una sociedad arraigada en las creencias populares, en el ritual, espera que su líder sea fuerte, fastuoso y un benefactor con su pueblo:

Desde el Ensayo sobre los dones (1925), de Marcel Mauss, sabemos que la autoridad en las sociedades no estatales se deriva de la capacidad de dar. Es poderoso quien "aplasta" al otro con su generosidad. Pese a la presencia del Estado, este principio ha seguido siendo válido para el campesino andino. Como se sabe, para obtener prestigio y autoridad en la comunidad, es preciso "pasar cargos", lo que supone siempre demostrar una gran generosidad. La autoridad resulta de esa generosidad, y también de la convicción compartida por todos de que el dirigente está cumpliendo un servicio a la comunidad. ${ }^{13}$

12. Ibíd.

13. Ibíd. 
Fotograma 2. Alcalde Juan Vargas, cegado por el poder, inventa tributos, apresa gente sin pruebas, un déspota iletrado

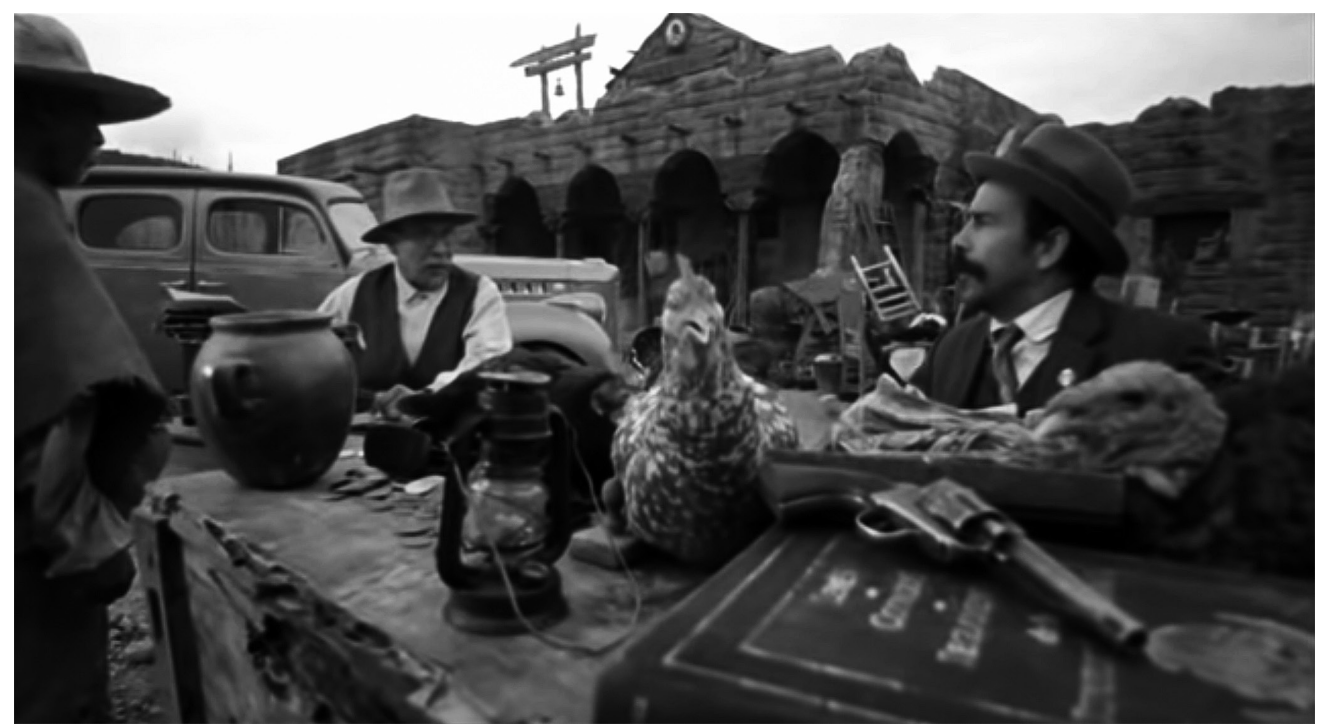

Fuente: Luis Estrada, La Ley de Herodes.

La colisión con el mundo europeo ocasiona en las formas de composición del poder una adaptación a los nuevos usos de acceder a favores de las personas y acceso de bienes, además de que los conflictos ya no solo se resolvían con la idea de negociar, sino de imponerse y ganarle uno al otro, incluso por la fuerza:

La situación se hace más compleja con la Conquista, a partir de la cual se descabezan las autoridades andinas, siendo reemplazadas por españoles. La relación con el poder -salvo con el poder interno al grupo familiar en el ayllu y la comunidad- se vuelve muy ambivalente: sumisión aparente y rebeldía latente. De algún modo, la sociedad andina se acomoda a los nuevos caudillos -sean estos blancos o no- porque le han sido impuestos por la fuerza, pero también porque reproducen formas tradicionales y conocidas de dominación. Pero este "acomodo" está también en tensión con otra tendencia tradicional de la sociedad andina: su milenaria voluntad de buscar resolver los conflictos de intereses mediante acuerdos entre las partes. ${ }^{14}$

Los grupos de parentesco constituyen la base de la organización social en una sociedad tradicional como la andina. Los andinos, mantienen por cultura una tendencia

14. Ibíd., 68-9. 
a la endogamia desde dentro (empresas familiares) y exogamia para las alianzas con otros grupos: "Al encerrarse en sí mismas las panacas se habrían entonces constituido en herramientas de poder muy fuertes, algo así como los partidos políticos de aquella época, pero su debilidad fue entonces que todas las demás se convertían en sus enemigos si se descuidaba establecer con ellas las tradicionales alianzas matrimoniales (y, por ende, también políticas)". ${ }^{15}$

En apariencia, para una sociedad como la peruana, los vínculos de parentesco son importantes en la vida política, donde, a partir de un discurso gerontocrático, se establece un buró que tome las decisiones y escoja dentro de sí o, por necesidad de asegurarse acceso al poder, elija desde fuera a un líder que sea identificado con la ideología de la organización política que pretende alcanzar el poder:

En la relación con el jefe, se presenta fácilmente la identificación con la persona, en la relación tradicional de poder. En la política moderna, esta práctica choca con la conformación de organizaciones políticas que pongan por delante, como base de su unidad, una ideología y un programa. La resolución del asunto se da, en partidos como el Apra o Sendero Luminoso, mediante la identificación de la ideología y del programa con el líder. Esta práctica va ligada a una tendencia hacia lo endógeno y el verticalismo. ${ }^{16}$

\section{EL DERECHO EN LA LEY DE HERODES}

El relato en imágenes de esta película sostiene un panorama rural de una localidad que puede pertenecer a cualquier país de Hispanoamérica. Se inicia con un linchamiento a un alcalde de un pueblo olvidado, y ante la falta de autoridad política, el partido político que alcanzó mayoritariamente el poder en México, le preocupa que esa sea una mala señal para otras localidades en donde pudiera replicarse este tipo de actividades, y, claro, para la reelección masiva. Es una plaza sin mayor trascendencia. Un pueblo pobre con pobladores indígenas vale poco para cualquier interés político, solo importa mantener la autoridad, aunque sea de manera figurativa.

Los de la capital necesitan un reemplazo para presidente municipal de San Pedro de los Saguaros, y estiman que como máximo estará solo por cuatro meses en el cargo, no tanto por el interés en la gobernabilidad del pueblo, sino por el cuidado de la imagen como partido político ad portas de las elecciones nacionales, pues ese tipo de eventos perjudican las aspiraciones al poder. El secretario de gobierno, licenciado López, ya tiene en mente quién va a ser el sucesor del decapitado alcalde:

15. Ibíd., 70 .

16. Ibíd., 72 . 
Fidel López: Voy a ser directo contigo, Vargas, como tú bien sabes, la modernidad por fin llegó a nuestro país, hay que concretar los ideales revolucionarios, hacer realidad las palabras del señor presidente Miguel Alemán, ayudar a que el país salga adelante, acabar con la corrupción y, sobre todo, con el desorden de algunos inconformes. Hay algunos funcionarios que no han entendido que deben servir al país, y se aprovechan para hacer negocios y enriquecerse a costa del pueblo; el país necesita de patriotas de verdad, de gente como tú. Juan Vargas: Gracias, licenciado

Fidel López: Voy a necesitar tu ayuda.

Juan Vargas: Usted dirá a quién hay que matar (risas)

Fidel López: No, no, no, Vargas, los tiempos han cambiado. ${ }^{17}$

La risa entra con amargura en esta representación de la corrupción del poder local, una decisión personal para elegir una autoridad, sobre la base de a quién se puede controlar y que no sea un peligro para los intereses del partido de gobierno. El escenario que nos muestra La Ley de Herodes es múltiple: desde las aspiraciones a tentar el poder nacional por una de las organizaciones políticas más tradicionales y "herederas" de la llamada revolución mexicana, manifiesta también la relación Norte (USA)-Sur (México), con la aparición de Robert Smith, "el gringo", parodiando cómo uno lo cree más tonto al otro. El medio rural también retrata la precariedad educativa y de infraestructura de las poblaciones rurales, y está también el escenario formal de la ciudad capital, del poder ejecutivo; qué más decir sobre el prostíbulo, negocio que a pesar de las carencias económicas del pueblo, florece, pues para todo puede faltar dinero, menos para las necesidades básicas de los hombres.

Para el flamante alcalde, todo le resulta de cabeza, un pueblo y gente pobre, indígenas que no hablan castellano, poderes paralelos en las figuras del cura de la parroquia, así como el médico, que incluso forma parte del partido opositor, quedándole claro que siempre le hacen trampa en las elecciones. Juan Vargas no puede ejercer ninguna autoridad, pues al ser un alcalde sin personalidad, sin presupuesto ni aparato técnico que lo apoye, solo le queda ser un elemento de adorno. Antes de que eso suceda, se dirige nuevamente a la ciudad capital para hacerle unos pedidos a su jefe:

Fidel López: ¿Para qué eres bueno?

Juan Vargas: Bueno, licenciado, no sé cómo empezar, quisiera ver la posibilidad de que me diera más presupuesto.

Fidel López: No, no, no Varguitas, no. Estamos muy próximos a las elecciones, y todo el presupuesto se tiene que ir al partido para que no tengamos sorpresas. Pídeme lo que quieras, lo que quieras, menos eso, no es el momento.

17. Luis Estrada, La Ley de Herodes. 
Juan Vargas: Bueno, ya que me da usted la oportunidad, quería ver si me puede cambiar de pueblo.

Fidel López: (risas)...¡Ah, chingao!... ahora sí me saliste más cabrón que bonito, ¡no!, ni madres, aquí es La Ley de Herodes, o te chingas o te jodes. Te voy ayudar, siéntate... ahí tienes, es un compendio de las leyes federales y las del Estado.

Juan Vargas: ¿Tengo que leerlo todo?

Fidel López: No, no, no, Varguitas. ¡Es para que tengas presupuesto! Si lo sabes usar, ya verás cómo a todo mundo le puedes sacar algo, entre multas, impuestos, licencias..., si usas la ley a tu conveniencia ya está todo listo. Recuerda, en este país, el que no tranza, no avanza. ${ }^{18}$

Vargas le explica a su jefe que en ese pueblo la gente no respeta a la autoridad, y López le enseña cómo ejercerla a golpes, le instruye en cómo hay que sacarle el dinero hasta al más rudo o sufrido campesino, y lo que finalmente él representa como autoridad delegada a ese pueblo:

Fidel López: Un remedio (saca una pistola de su escritorio). Ahí tienes. ¡Anda, hombre, tómala! Si alguien te amenaza con un machete, le sacas la pistola y vas a ver cómo nadie se te pone al brinco (Vargas percuta la pistola). Guárdala, guárdala, hombre, guárdatela ahí dentro, no vayas a matar a algún cabrón por ahí, y recuerda que todo lo que está aquí en este librito, que diga poder Ejecutivo, Legislativo y Judicial, eso eres tú. La máxima autoridad de San Pedro... de qué madres o cómo se llame...

Juan Vargas: San Pedro de los Saguaros.

Fidel López: ¡San Pedro de los Saguaros! Ya tienes, dale, guárdate la pistola, hombre.

Juan Vargas: Gracias, licenciado.

Fidel López: Ahí tienes. ¡Y ahora sí!, con el librito y la pistola, a ejercer la autoridad.

Juan Vargas: Gracias, licenciado.

Fidel López: Pásale (risas). ${ }^{19}$

Con el conocimiento de la ley se da inicio a la peor versión de Juan Vargas, corrupto, mentiroso, ebrio, timador, llega a ser un todopoderoso regente del pueblo, de aquel lugar del que no saldría nunca para cobrar un miserable impuesto. Vargas comenzaba a hacer su fortuna producto de las extorsiones, "mordidas" y demás, también como producto de utilizar la ley a su conveniencia y tener de soporte el revólver que su jefe le había dado. Es que la ley sin respaldo armado le quita eficacia, y es así como lo han entendido este par de pillos.

18. Ibíd.

19. Ibíd. 
Para ello tuvo que estudiar la legislación vigente, y de ahí se va al burdel de "la Lupe" a hacer efectivo el cobro de impuestos y faltas que, según su entender y ver, se habrían vulnerado. "La Lupe" se le enfrenta, lo trata sin respeto a su autoridad; llega un momento en que Vargas saca su pistola para enfrentar el machete de "la Lupe", terminando en un confuso incidente en donde se le escapa un tiro al alcalde que termina por herir a la administradora del burdel.

Todo parecía haber acabado aquí, en su primera aventura con la ley y la pistola; sin embargo, quien mejor entiende que había que hacer caso al alcalde es "la Lupe", que va hasta la casa municipal a conversar con Vargas y señalarle que no hay rencor y que, de una vez por todas, acepte la "mordida", y es ahí cuando vemos aquello que en Vargas se convertirá en actividad cotidiana: pedir, exigir y recibir "mordidas" de cuanto incauto habitante se atreva a faltar a la ley. Para iniciarlo en la corrupción, "la Lupe" le señala su opinión respecto del conocimiento de la ley. Lupe a Vargas: "Es que eso nada más lo sabes tú, porque lees ese librote". Entonces (el alcalde acepta la "mordida") y en señal de conformidad, la doña le dice: "Ya nos vamos entendiendo, licenciadito, me saliste más cabrón que bonito".

Acto seguido, se deshace de todos sus rivales políticos, entre ellos el más peligroso, que es el doctor Morales. Para ya no tenerlo de contendiente, va a consultarle al cura del pueblo, y este le vende uno de los pecados de Morales: abuso sexual por parte del doctor a la menor de edad que criaba en su casa. Así que logra espantar a su rival, quien tiene que irse del pueblo.

Si ya parecía poco, la transformación del personaje, de ser un humilde y anónimo chatarrero que estaba inscrito como miembro del partido de gobierno, pasa de la noche a la mañana a ser alcalde, y de ahí a ser un corrupto, cobracuentas. Aún quedaba, para superar dicha fase, ya perdida la razón, convertirse en legislador, juez y comisario, todo en uno, más corrupto que antes, y como ya no había dinero que sacarle a la población, comienza a meter presos a todos aquellos que no pueden pagarle. Con todo lo que parezca, esas leyes, que le sirvieron para extorsionar y hacerse de un considerable botín, ya le resultaban una traba para sus aspiraciones, comienza a cambiar la Constitución, los plazos, los montos, todo aquello que considera inútil o muy poco provechoso para su interés.

Esto atrae el interés de sus jefes en la capital del país, donde llegan las noticias de que hay un alcalde en un pueblo miserable, que no se sabe cómo hizo, pero que se está llenando de dinero. Su propio superior, Fidel López, llega en persona a ver si realmente había reunido una fortuna, y lo hace acompañado de un matón, pero ya tenía enfrente a un Vargas alcohólico, con problemas de infidelidad de su esposa, y al "gringo" Smith y a todo el pueblo en su contra. Logra zafarse de su captor y termina matando a su jefe: "Lo siento, licenciado, es usted o yo, yo estaba yendo bien, pero ahí va a calentarme la cabeza, que tú eres la ley, que la única autoridad, que la Ley de He- 
rodes". Ebrio de poder, la población lo busca, tal como dio inicio la película. Era hora de deshacerse del impopular y abusivo alcalde. A diferencia de los anteriores, Vargas se salva de ser linchado, y como se ve en los minutos finales, llega al Parlamento Nacional reconociendo que el camino lo ha tenido teñido de sangre, y en polémica administración municipal, todos le aplauden cualquier parecido, ¿Cree usted que está confundiendo la realidad con la ficción? ¿O al revés?

\section{CONCLUSIONES}

Una película como La Ley de Herodes sirve para el diálogo de temas difíciles como el de la corrupción y sus connotaciones que terminan desarrollando una cultura de la ilegalidad, donde se conocen los mandatos imperativos y dispositivos de la ley, pero no se las reconoce y menos se las obedece o utiliza adecuadamente, esto genera el debilitamiento de las instituciones del Estado y da la peligrosa apariencia de que vivir en la marginalidad, no pagando impuestos y no respetando a la autoridad es la manera más beneficiosa para progresar, por creer que es más rápido, inmediato y con resultados el aceptar que la corrupción agiliza el paso. Esto realmente es más perjudicial, promueve el fomento de que las mismas autoridades, así como el alcalde Juan Vargas, terminen siendo quienes desvién su autoridad al servicio de su propia persona o de una organización criminal que podría terminar envuelta bajo el manto de una organización política. Ya no es que hay criminales que quieran acabar o ser socios del Estado, sino criminales que forman parte del Estado, y así nos encontramos a merced de la anarquía.

El cine sirve también -a través de imágenes-, para conocer el diálogo tradicional de las instituciones jurídicas, en este caso las de carácter municipal, que permite discutir desde otra perspectiva estos temas que resultan difíciles de ejemplificar por ser políticamente incorrecto hablar de ellos - más difícil hablar de los que corrompen que de los corruptos-, logra sostener con el auditorio una posibilidad de ejercitar indignación por cómo es vulnerado el estado de derecho por las propias autoridades elegidas para defenderla. El cine somete al escrutinio del auditorio el porqué elegimos tan mal y por qué alguien como un Juan Vargas, que en sus inicios quería hacer bien las cosas atinentes a un gobierno municipal, termina convirtiéndose en un engranaje de un gobierno nacional criminal.

\section{BIBLIOGRAFÍA}

Ansión, Juan. "Autoridad y democracia en la cultura popular: una aproximación desde la cultura andina”. Allpanchis Phuturinga, n. 33 (1989): 59-79. 
Apuleyo Mendoza, Plinio, Carlos Alberto Montaner y Álvaro Vargas Llosa. Manual del perfecto idiota latinoamericano. Barcelona: Plaza \& Janés, 1996.

Bourricaud, François. Poder y sociedad en el Perú contemporáneo. Lima: Instituto de Estudios Peruanos, 2017.

Carnelutti, Francesco. Cómo nace un proceso. Bogotá: Temis, 2012.

Colegio de Abogados de Lima. Revista del Foro, año LIII, n. 2 (mayo-agosto 1966).

Estrada, Luis. La Ley de Herodes. DVD. México: Bandidos Films, 1999.

Ford Coppola, Francis, et al. Así de simple 2: encuentros sobre cine. Bogotá: Voluntad, 1995.

García Calderón, Francisco. Diccionario de la legislación peruana, 2. ${ }^{\text {a }}$ ed. Lima: Imprenta del Estado, por E. Aranda, 1977.

Huber, Ludwig. Romper la mano. Una interpretación cultural de la corrupción. Lima: Instituto de Estudios Peruanos / Proética, 2008.

Martel, Frédéric. Cultura Mainstream. Cómo nacen los fenómenos de masas. Madrid: Taurus, 2011.

Martins, Daniel Hugo. "Regímenes municipales contemporáneos”. En El Municipio, editado por Jorge R. Vanossi. Buenos Aires: Ediciones Ciudad Argentina, 1984.

Pajuelo Teves, Ramón. Participación politica indígena en la sierra peruana. Una aproximación desde las dinámicas nacionales y locales. Lima: Instituto de Estudios Peruanos / Fundación Konrad Adenauer, 2006.

Perú. Constitución Política del Perú. 29 de diciembre de 1993.

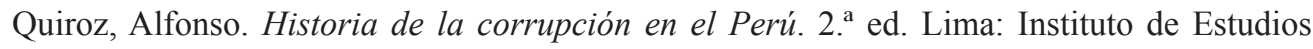
Peruanos, 2013.

Savater, Fernando. Política para Amador. Barcelona: Ariel, 1993.

Servan-Schreiber, Jean-Jacques. El poder regional. Manifiesto de 1971. Barcelona: Dopesa, 1971.

\section{Películas sugeridas sobre el tema de alcaldes}

1. Don Camilo (1952)

2. ¡Bienvenido, Mister Marshall! (1953)

3. Xoxontla: Tierra que arde (1976)

4. Sor Batalla (1990)

5. La vida es una sola (1993)

6. La Ley de Herodes (1999)

7. Matchmaking Mayor (2010)

8. Escándalo americano (2013) 